\section{Outcome determinants in acute lung injury P248 MEASURING PHYSICAL RECOVERY IN THE CRITICAL CARE POPULATION: DEVELOPMENT OF THE CHELSEA CRITICAL CARE PHYSICAL ASSESSMENT TOOL (CPAX)}

doi:10.1136/thx.2010.151068.49

${ }^{1} \mathrm{E} J$ Corner, ${ }^{1} \mathrm{H}$ Wood, ${ }^{1} \mathrm{C}$ Englebretsen, ${ }^{2} \mathrm{~S}$ Boot, ${ }^{3} \mathrm{D}$ Nikoletou. ${ }^{1} \mathrm{C}$ elsea and Westminster Hospital NHS Trust, London, UK; ${ }^{2}$ Barts and The London NHS Trust, London, UK; ${ }^{3}$ St George's, University of London, London, UK

Introduction The secondary physical effects of critical illness, for example, muscle atrophy, can be detrimental to functional outcome and quality of life in critical care survivors. To minimise these problems early physiotherapy in the Intensive Care Unit (ICU) is advocated. However, research to identify the optimal rehabilitation strategy is hindered by lack of an ICU specific objective measure of physical recovery. Current measures are either impairment specific, thus not capturing the full picture, or their validity is unproven in this population.

Aim To develop a measurement tool to assess physical recovery in the heterogeneous general adult critical care population.

Method Face/content validity The initial tool was developed in a clinical setting by specialist physiotherapists and is called the Chelsea Critical Care Physical Assessment tool (CPAx). It is a pictorial composite of 10 numerical evaluations of pertinent functions and impairments. It was tested for face and content validity with a content validity index questionnaire (CVIO), a subsequent focus group and a repeat CVIO.

Inter-rater reliability Five physiotherapists using the CPAx regularly all assessed the same two patients. Data were analysed for intraclass correlation co-efficient (ICC) and internal consistency.

Construct validity A dual centred cohort study of 32 ICU patients was completed. Treating physiotherapists assessed patients using the CPAx thrice weekly. Additionally, biceps and quadriceps strength, cough peak flow (CPF) and components of the AusTOMs scores (a physiotherapy outcome measure) were tested by a researcher blinded to the CPAx scores. Correlation co-efficients were then used to analyse the data.

Results Face/content validity Pre and post focus group CVIs were 0.67 ( $p>0.05)$ and $0.83(p<0.05)$, respectively.

Reliability Reliability was strong with internal consistency of 0.98 and ICC 0.902 (95\% CI 0.799 to $0.969 ; \mathrm{p}=<0.001$ ).

Construct validity Pilot data showed strong positive correlations (0.744-0.922, $\mathrm{p}<0.01)$, between the CPAx, muscle strength and AusTOMs scores. Data were insufficient to analyse CPF results.

Conclusion Preliminary data show that the CPAx is a reliable and valid measure of physical function in ICU patients. It can now be used as an outcome measure for physiotherapy research and has potential to act as a predictor of functional outcome in the ICU population.

Abstract P248 Table 1 Construct validity data

\begin{tabular}{|c|c|c|c|c|c|c|c|c|}
\hline & $\begin{array}{l}\text { Aus- } \\
\text { TOMs } \\
\text { BPCA }\end{array}$ & $\begin{array}{l}\text { Aus- } \\
\text { TOMs } \\
\text { BPCI }\end{array}$ & $\begin{array}{l}\text { Aus- } \\
\text { TOMs } \\
\text { MSKA }\end{array}$ & $\begin{array}{l}\text { Aus- } \\
\text { TOMs } \\
\text { MSKI }\end{array}$ & $\begin{array}{l}\text { Left } \\
\text { Quad- } \\
\text { riceps }\end{array}$ & $\begin{array}{l}\text { Right } \\
\text { Quad- } \\
\text { riceps }\end{array}$ & $\begin{array}{l}\text { Left } \\
\text { Biceps }\end{array}$ & $\begin{array}{l}\text { Right } \\
\text { Biceps }\end{array}$ \\
\hline $\begin{array}{l}\text { Correlation } \\
\text { Coefficient } \\
\text { with the } \\
\text { CPAx score }\end{array}$ & $0.922^{*}$ & $0.892^{*}$ & $0.888^{*}$ & $0.844^{*}$ & $0.756^{*}$ & $0.765^{*}$ & $0.744^{*}$ & $0.752^{*}$ \\
\hline $\begin{array}{l}\text { Number of } \\
\text { patient } \\
\text { measurements }\end{array}$ & 42 & 40 & 42 & 41 & 42 & 42 & 42 & 42 \\
\hline
\end{tabular}

${ }^{*}$ Correlation is significant to the level $\mathrm{p}=0.01$.

AusTOMs BPCA, balance and postural control activity section of the AusTOMs tool; AusTOMsBPCI, balance and postural control impairment section of the AusTOMs tool; AusTOMs MSKA, musculoskeletal activity section of the AusTOMs; AusTOMs MSKI, musculoskeletal impairment section of the AusTOMs.
P249 PHYSICIANS' OPINION: CEILINGS OF THERAPY IN CHRONIC OBSTRUCTIVE PULMONARY DISEASE (PILOT STUDY)

doi:10.1136/thx.2010.151068.50

${ }^{1} \mathrm{~J}$ L Gallagher, ${ }^{2} \mathrm{~B}$ Morton, ${ }^{3} \mathrm{I}$ Clegg, ${ }^{2} \mathrm{~J}$ Walker, ${ }^{1} \mathrm{~L}$ Davies. ${ }^{1}$ Aintree University Hospital Foundation Trust, Liverpool, UK; ${ }^{2}$ Royal Liverpool University Hospital Trust, Liverpool, UK; ${ }^{3}$ Central Manchester University Hospitals NHS Foundation Trust, Manchester, UK

Introduction Acute exacerbations of chronic obstructive pulmonary disease (COPD) are a common reason for hospital admission. Treatment depends upon the severity of presentation and background physiological status. The COPD NICE guidelines (2010) state that when patients are started on NIV, there should be a clear plan covering what to do in the event of deterioration and ceilings of therapy should be agreed. ${ }^{1}$ We sought to explore decision making among clinicians with responsibility for interventional treatments in difficult scenarios.

Method We questioned intensive care and respiratory clinicians in two deaneries. We described six hypothetical patients with COPD who presented to an A\&E department in hypercapnic respiratory failure. The histories given were of end stage COPD, ischaemic heart disease, complicated diabetes mellitus, advanced age, potentially curable bronchial carcinoma and non-concordance with treatment. Results One hundred and thirteen questionnaires were collected; 58 intensive care medicine (ICM) clinicians (28 consultant and 30 specialist trainees) and 55 respiratory medicine physicians (13 consultant and 42 specialist trainees). The majority of respondents would intervene in the presented scenarios, either with invasive or non-invasive ventilation as illustrated in graph 1 . No statistical difference in decision making was demonstrated between ICM and respiratory clinicians. Statistical kappa analysis (Intercooled Stata 9.0) demonstrated 'fair' agreement among ICM trainees, respiratory trainees and consultants when choosing non-invasive (0.32, 0.41, $0.33)$ and invasive ventilation $(0.29,0.39,0.36)$ with 'slight' agreement among ICM consultants (non-invasive 0.12 and invasive ventilation 0.22 ). Some respiratory physicians felt that they required additional information, such as results of spirometry, to make informed decisions. However, in an acute setting, such information is often unavailable so was not included in the vignettes. The opportunistic nature of data collection meant that a response rate could not be calculated.

Conclusion This pilot study did not demonstrate a difference in decision making between respiratory and intensive care specialities. With development of the vignettes this methodology could form the basis for a national survey on ceilings of therapy in COPD to inform the individual clinician when making difficult decisions.

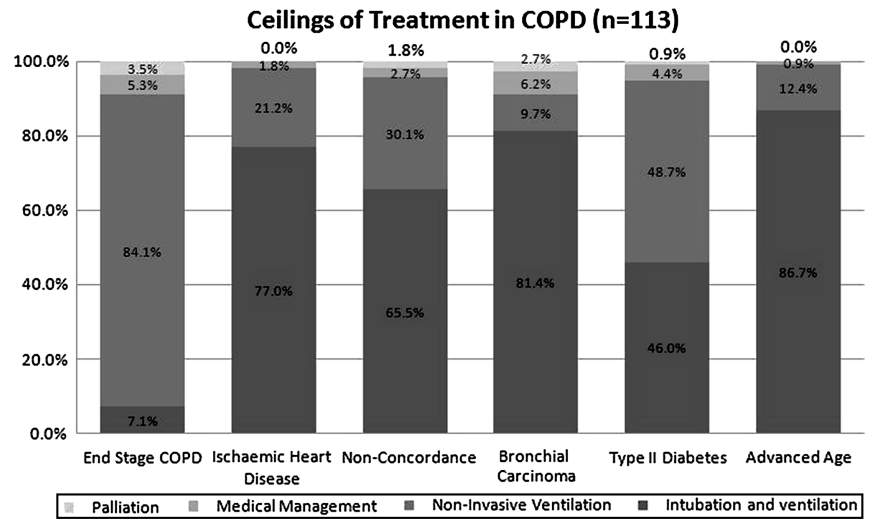

Abstract P249 Figure 1 


\section{REFERENCE}

1. http://guidance.nice.org.uk/CG101/Guidance/pdf/English.

\section{P250 INCIDENCE, CLINICAL PROFILE AND OUTCOMES OF VENTILATOR-ASSOCIATED PNEUMONIA IN A TERTIARY HOSPITAL}

doi:10.1136/thx.2010.151076.1

R M Panaligan, J P Guiang. University of Santo Tomas Hospital Department of Medicine, Manila, Philippines

Background Pneumonia is still the most important nosocomial infection among critically ill patients receiving mechanical ventilation despite advancement in the diagnostic technology available, introduction of new antimicrobials and employment of preventive strategies. Our aim was to prospectively identify the occurrence of ventilator-associated pneumonia (VAP) in a tertiary hospital as well as to determine its clinical profile and outcomes.

Methods A prospective, observational study was performed including 52 patients with VAP in a tertiary hospital. All adult patients admitted who required mechanical ventilation regardless of site of care was included and followed up until successful weaning, discharge or death.

Results During the 12-month study period (1 May 2009-30 April 2010), a total of 52 patients (7.6\%) developed VAP among the 686 patients who received mechanical ventilation. Most common comorbid conditions documented were diabetes mellitus and hypertension. Higher APACHE II scores ( $p \leq 0.001)$, inappropriate antimicrobial use $(p=0.027)$ and the presence of underlying malignancy $(p=0.03)$ are correlated with mortality. The most common pathogen isolated was Pseudomonas aeruginosa (23\%) and carbapenems as the most commonly used antimicrobial. Mortality rate was $38.5 \%$. Non-survivors had numerically longer ICU stay and length of mechanical ventilation (Abstract P250 Table 1).

Abstract P250 Table 1

\begin{tabular}{|c|c|c|c|c|}
\hline & $\begin{array}{c}\text { Non-Survivors } \\
(n=20)\end{array}$ & $\begin{array}{c}\text { Survivors } \\
(\mathrm{n}=32)\end{array}$ & $\begin{array}{l}\text { Total } \\
\left.(n=)^{2}\right)\end{array}$ & p-value \\
\hline Age & $68.5 \pm 14.68$ & $63.59 \pm 17.26$ & $65.48 \pm 16.34$ & 0.297 (NS) \\
\hline \multicolumn{5}{|l|}{ Gender } \\
\hline Male & $9(45 \%)$ & $21(65.63 \%)$ & $30(57.69 \%)$ & $0.162(\mathrm{NS})$ \\
\hline Female & $11(55 \%)$ & $11(34.38 \%)$ & $22(42.31 \%)$ & \\
\hline \multicolumn{5}{|l|}{ Ward Type } \\
\hline Clinical division & $5(25 \%)$ & $11(34.38 \%)$ & $16(30.77 \%)$ & 0.549 (NS) \\
\hline Pay division & $15(75 \%)$ & $21(65.63 \%)$ & $36(69.23 \%)$ & \\
\hline \multicolumn{5}{|l|}{ Co-morbidities } \\
\hline Hypertension & $6(30 \%)$ & $16(50 \%)$ & $22(42 \%)$ & 0.25 (NS) \\
\hline Diabetes Mellitus & $11(55 \%)$ & $14(44 \%)$ & $25(48 \%)$ & 0.57 (NS) \\
\hline $\mathrm{COPD}^{*}$ & $2(10 \%)$ & $2(6 \%)$ & $4(8 \%)$ & 0.63 (NS) \\
\hline Underlying Malignancy & $7(35 \%)$ & $3(9 \%)$ & $10(19 \%)$ & 0.03 \\
\hline Renal Failure & $1(5 \%)$ & $6(19 \%)$ & $7(13 \%)$ & 0.23 (NS) \\
\hline$C A D^{* *}$ & $4(20 \%)$ & $2(6 \%)$ & $6(12 \%)$ & 0.19 (NS) \\
\hline \multicolumn{5}{|l|}{ Reason for Intubation } \\
\hline Medical & $17(85 \%)$ & $21(65.63 \%)$ & $38(73.08 \%)$ & 0.200 (NS) \\
\hline Surgical & $3(15 \%)$ & $11(34.38 \%)$ & $14(26.92 \%)$ & \\
\hline \multicolumn{5}{|l|}{ VAPOnset } \\
\hline Early & $11(55 \%)$ & $22(68.75 \%)$ & $33(63.46 \%)$ & 0.382 (NS) \\
\hline Late & $9(45 \%)$ & $10(31.25 \%)$ & $19(36.54 \%)$ & \\
\hline \multicolumn{5}{|l|}{ Definite Etiology } \\
\hline Without & $5(25 \%)$ & $9(28.13 \%)$ & $14(26.92 \%)$ & 1.000 (NS) \\
\hline With & $15(75 \%)$ & $23(71.88 \%)$ & $38(73.08 \%)$ & \\
\hline With Monemicrobial & $9(60 \%)$ & $13(56.52 \%)$ & $22(57.89 \%)$ & \\
\hline With Pojymicrokial & $6(40 \%)$ & $10(43.48 \%)$ & $16(42.11 \%)$ & \\
\hline \multicolumn{5}{|c|}{$\begin{array}{l}\text { Appropriateness of Empiric } \\
\text { Antibiotics }\end{array}$} \\
\hline Yes & $4(20 \%)$ & $18(56.25 \%)$ & $22(42.31 \%)$ & 0.027 \\
\hline No & $9(45 \%)$ & $6(18.75 \%)$ & $15(28.85 \%)$ & \\
\hline Unknown & $7(35 \%)$ & $8(25 \%)$ & $15(28.85 \%)$ & \\
\hline \multicolumn{5}{|l|}{ Number of Drugs } \\
\hline Menotherapy & $10(50 \%)$ & $18(56.25 \%)$ & $28(53.85 \%)$ & 0.777 (NS) \\
\hline Combination & $10(50 \%)$ & $14(43.75 \%)$ & $24(46.15 \%)$ & \\
\hline \multicolumn{5}{|l|}{ ConcomitantInfection } \\
\hline With & $9(45 \%)$ & $20(62.5 \%)$ & $29(55.77 \%)$ & 0.260 (NS) \\
\hline Without & $11(55 \%)$ & $12(37.5 \%)$ & $23(44.23 \%)$ & \\
\hline Mean APACHEII score & $27.25 \pm 6.26$ & $20.88 \pm 5.59$ & $23.33 \pm 6.59$ & 0.000 \\
\hline
\end{tabular}

Conclusion In our setting, current VAP incidence rate is $7.6 \%$ with mortality of $38.5 \%$. This highlights the current magnitude of VAP which should prompt hospital administrators and health care workers to complement rational antibiotic use with non-pharmacologic strategies to at least decrease VAP incidence and alleviate its burden especially in a developing country.

\section{P251 FLOW CYTOMETRIC DETECTION OF INTRACELLULAR ACTIVATION MARKERS OF PULMONARY CELLS DURING ACUTE LUNG INJURY}

doi:10.1136/thx.2010.151076.2

A C Waite, K P O'Dea, M R Wilson, M Takata. Section of Anaesthetics, Pain Medicine and Intensive Care, Imperial College, London, UK

Background Activation of intracellular signalling cascades such as mitogen-activated protein (MAP) kinase pathways has been implicated in various animal models of acute lung injury. However, such data rely almost exclusively on measurements within whole lung homogenate samples, so little information is available regarding cell type specific processes. In order to address this, we have developed a flow cytometric technique to identify discrete pulmonary cell populations and examine their early activation in terms of phosphorylation of intracellular MAPkinase pathway intermediates (ERK, p38 and its downstream target MK2).

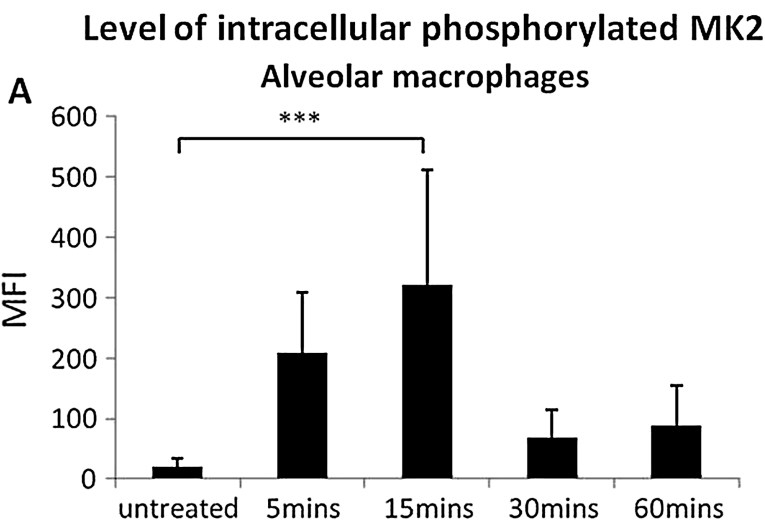

B

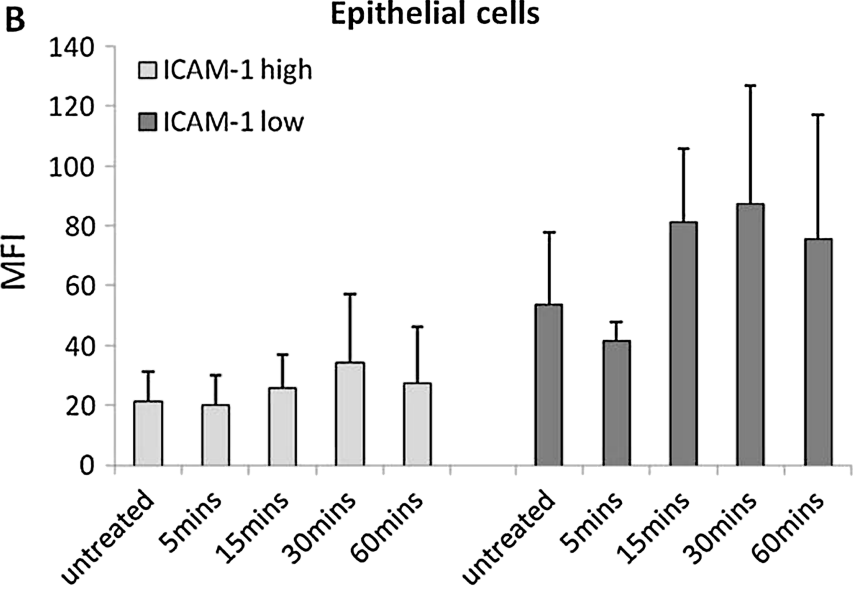

$N=4-8$. Data shown as mean + s.d. *** $p<0.001$ by ANOVA with Bonferroni tests

Abstract P251 Figure 1 Level of intracellular phosphorylated MK2. A. Alveolar macrophages. B. Epithelial cells. 